\section{Comment on the editorial} 'The secret ways of scientists' in EMBO reports, December 2000

I read 'The secret ways of scientists' with much interest and in principle I closely share the view expressed there. However, I am rather suspicious that such a view no longer reflects the truth. It appears to me that the tendency among scientists to start their own biotech companies may lead to a corruption of values and create a rather strange mixture of attitudes. The editorial states that 'our collective behaviour is not that of a business [...] nor is it the behaviour of sportsmen [...].' I cannot help but question this point of view. I think, starting a commercial activity, in addition to our academic or research tasks, inescapably includes to a high degree the danger that primary duties are neglected in favour of the development and promotion of the company-an obvious conflict of interest. Therefore, I wonder how far this statement can be relied on in the future. It is my opinion that university scientists and researchers have to make a decision to dedicate their time, efforts and energy to one of the two-'money or the gruelling quest for answers'. To combine both is probably incompatible. On the other hand, if it were simply in the sense of true 'sportsmanship', I would not suspect incompatibility because sportsmanship seems more a feature of the personal character.

I also think that the involvement of an academic researcher in her or his company must become an obstacle when talking to the public. It will undermine the credibility of scientists making statements on their attitudes and behaviour as you have described them. In addition, the more recent developments related to gene technology, such as patenting, show that in fact, scientific results are often no longer generally available, except with delay-if at all. This will also have an effect on the credibility of scientists with the public, even if keeping research data secret were an attitude restricted to commercial researchers, which it is not any more.

I am not sure how to deal with such a situation because it reflects developments that we cannot-or might not want tochange.

\section{Wolfgang Hennig}

Faculty of Biology, Johannes Gutenberg University Mainz, Germany

DOI: 10.1093/embo-reports/kve031

\section{Comment on the editorial 'Back to Darwin?' in $E M B O$ reports, November 2000}

I very much enjoyed, and support the views you expressed in 'Back to Darwin?' Charles Darwin was an indefatigable observer, but it is likely that he already had a hypothesis in mind. If Darwin was, in fact, an indefatigable hypothesis-tester, it is likely that the cultural climate in which he worked induced him to disguise the fact. There is much evidence, for example, that the 'big' idea of evolution by natural selection could well have predated the voyage on The Beagle.
Be that as it may, I do think there is a lot of nonsense now being talked and written about hypothesis-free research in the context of bioinformatics and genomics, as if these powerful techniques in some way alter the way in which we try to understand the world. As I think you imply, there is a real danger in science policy of investing everything in the idea that 'cranking the handle' of a new and more powerful machine will, by itself, generate new knowledge.

Bioinformatics, genomics and other examples of large-scale data collection again raise Karl Popper's question of which is a better metaphor for scientific enquiry - the bucket or the searchlight. Even the oceans of data from DNA microarrays cannot be converted into knowledge or understanding by being scooped up, at random, as if in buckets. Knowledge is more than information. We do not trawl for meaning, we go looking for it. So we select what we examine with care. Our intention, in selecting what to look for, is to compare the results of experiments with the predictions of our hypotheses, to see if the results coincide with the predictions.

The sum of the data we can collect is too vast to mean anything. So we look, purposefully, to see if any part if it resembles our expectations. Science is a searchlight-we have to first decide where to point it, and why.

John F. Allen

Department of Plant Biochemistry, Lund University, Sweden

DOI: 10.1093/embo-reports/kve041 